By Karl-Heinz Szekielda, Dennis J. Suszkowski, and Paul S. Tabor, College of Marine Studies, University of Delaware, Newark, Delaware

\begin{abstract}
The upwelling off the NW coast of Africa in the vicinity of Cape Blanc was studied in February March 1974 from aircraft and in September 1973 from Skylab. The aircraft study was designed to determine the effectiveness of a differential radiometer in quantifying surface chlorophyll concentrations. Photographic images of the S190A Multispectral Camera and the S190B Earth Terrain Camera from Skylab were used to study distributional patterns of suspended material and to locate ocean color boundaries. The thermal channel of the S192 Multispectral Scanner was used to map sea-surface temperature distributions offshore of Cape Blanc. Correlating ocean color changes with temperature gradients is an effective method of qualitatively estimating biological productivity in the upwelling region off Africa.
\end{abstract}

\title{
INTRODUCTION
}

From a practical standpoint, phytoplankton is a very important life form in the ocean, since primary productivity can be directly related to potential production of commercial fish. In upwelling regions of the world, such as off the Northwest coast of Africa, wind stress produces an offshore movement of surface waters which are replaced by cooler, nutrient-rich subsurface waters. These upwelled waters are an excellent medium for the propagation of phytoplankton. Though upwelling regions comprise only about one-tenth of 1 percent of the ocean surface, Ryther (1969) estimates that they produce about half of the world's fish supply.

When studying plankton over large areas of the ocean, oceanographers face serious logistics problems. Since it may take several days to several weeks to cover a large study area by ship, the best that can be hoped for is a time-averaged picture of plankton distributions. The ship sampling program may miss patches of plankton of significant interest and the concentrations may be changing rapidly over time. Since large surface areas of the ocean can be easily seen from space, the possibility of synoptically determining plankton quantities and distributions from earth orbit is extremely attractive.

On 4 September 1973, the Skylab spacecraft passed directly over the Cape Blanc section of NW Africa. This report will summarize the interpretation to date of radiometeric data derived from Skylab as it pertains to plankton distributions off the African coast.

\section{ATMOSPHERIC CONDITIONS}

The NW coast of Africa can be effectively studied from space, since favorable meteorological conditions are present throughout most of the year. During winter in the Northern Hemisphere, a high pressure system is centered between the Canary Islands and the Azores. In summer, this system extends further to the north and west. Therefore, the coast of Africa experiences clear weather during most of the year with extremely good horizontal and vertical visibility. 
The NE trade winds are responsible for the upwelling conditions off the NW African coast. During the summer months when the Trades are located between $15^{\circ} \mathrm{N}$ and $35^{\circ} \mathrm{N}$ latitude, the principal component of the winds is northerly, therefore giving rise to the most intense upwelling conditions. (Szekielda, 1973).

Figure 1 shows a Nimbus 5 thermal image of the NW coast of Africa taken 2 September 1973, 2 days prior to the Skylab overpass. The clear conditions surrounding Cape Blanc indicate the influence of the offshore anticyclone and the low-moisture NE trade winds. The band of thick clouds to the south represents the Intertropical Convergence Zone.

\section{SPECTRAL PROPERTIES OF PLANKTON}

Light penetration in water is affected by plankton, algae, and dissolved and suspended matter. As a result, the composition of backscattered light from below the air-sea interface is determined by the nature of the constituents in the water column. In contrast to the absorption spectrum of chemically-pure chlorophyll in solution, algae suspensions absorb and scatter light more uniformly throughout the visible part of the electromagnetic spectrum. Because of the spectral absorption and scattering properties of plankton, its concentration can be estimated by measuring the spectral backscattered radiance over water.

When monitoring plankton or biomass from high altitudes, we must consider the fact that algae behave more like a suspension than a pure solution of chlorophyll. As a result, solar light will be scattered at the outer shell of the plankton organisms. The absorption of incident irradiance by the cells depends on their outer structure and the optical density inside the cell. Variation in the optical density or the configuration of the cells may change the intensity of backscattered light even if the incident solar irradiance, sun angle, and chlorophyll concentration per unit of volume remain constant. Yentsch (1960) found that the red absorption band of chlorophyll has little influence on water color. This means that the signal obtained with a red band sensor would record primarily the effect of backscattered light from the organisms.

The intensity of backscattered light caused by plankton and dissolved matter from the ocean as a function of wavelength is given in Figure 2. Gulf Stream water was used as a reference water assuming that the chlorophyll concentration of less than $0.02 \mu \mathrm{g} \cdot 1^{-1}$ does not change significantly the backscattered light compared to pure water. It was assumed, for the interpretation of the different spectra, that sky conditions, sun angle, and sea state were the same over both sites. The spectrum in Figure 2 is the difference in energy between the spectrum obtained in near-coastal water and the spectrum recorded over the Gulf Stream.

If both water masses had the same optical characteristics and oceanic conditions, the energy difference in both spectra should be equal to zero. Any differences between the two signals would thus be caused by dissolved and/or particulate matter in the sea. If chlorophyll affected the backscattered light by its absorption properties in the shorter wavelengths, we would expect differences near the absorption bands of chlorophyll.

Chlorophylls have two main absorption maxima in the visible region of the electromagnetic spectrum. The main absorption peaks for pure chlorphyll $a$ are at $0.446 \mu \mathrm{m}$ and $0.663 \mu \mathrm{m}$. However, the naturally occurring chlorophyll $a$ types in plants have spectra with peaks near 0.673 and $0.683 \mu \mathrm{m}$. Other forms show maxima near 0.690 and $0.710 \mu \mathrm{m}$.

The spectrum in Figure 2 shows that the first and the second absorption bands of chlorophyll have only a minor influence on the total backscattered light. Strong absorption appears at about $0.72 \mu \mathrm{m}$, but 
the maximum of backscattered light appears at $0.58 \mu \mathrm{m}$. Considering only the portion between the second absorption band and the near-infrared, it can be seen that only a linear decrease of backscattered light appears. This is an indication that in addition to the absorption of light by chlorophyll, backscattered light from the organisms themselves contributes to the total backscattered energy. Thus, the size and concentration of particles or marine organisms seem to be the important contributors to the changes in backscattered light intensity as measured in the Skylab sensors. The scattering intensity of suspended particles is proportional to $\lambda^{-n}$ where $\lambda$ is the wavelength and $n$ the Rayleigh value which may vary from 4 for pure water to 0 at high turbidity. In other words, the intensity of backscattered light increases with particle concentration. This shows the important influence of particles without chlorophyll on the backscattered light from below the sea surface. Lorenzen (1970) established a correlation between surface chlorophyll concentrations and primary productivity for different oceanic waters. Better correlations were found when chlorophyll and primary productivity data from the upwelling region off the NW coast of Africa were compared. This suggests that a significant relationship between the two parameters can be obtained when individual oceanic regions are studied, thus making surface chlorophyll measurements that much more valuable.

An often suggested algorithm of narrow band ocean color reflectances was employed in an aircraft mission for evaluation of its effectiveness in chlorophyll determination and in recognition of changes in regional ocean color distributions. A ratio of the $0.443 \mu \mathrm{m}$ to the $0.525 \mu \mathrm{m}$ reflectances has been discussed by Clarke and Ewing (1974) and Duntley (1972) as having the ability to determine chlorophyll concentration in near-surface waters from aircraft and satellite altitudes. From these observations Arvesen et. al. (1973) developed a differential correlation radiometric method to detect chlorophyll. Their measurements of ratio values using the continuous recording differential radiometer, correlated well with real-time sea-truth measurements of surface chlorophyll concentrations. From the results of flights over various types of water masses, a calibration of the reflectance ratio to surface chlorophyll concentrations $\left(\mathrm{mg} / \mathrm{m}^{3}\right)$ was constructed.

During February and March 1974 the differential radiometric (DR) method was used in extensive oceanographic aircraft missions as part of the JOINT-I project in a 1 square degree region $\left(20^{\circ}-21^{\circ} \mathrm{N}\right.$. latitude $\times 17^{\circ}-18^{\circ} \mathrm{W}$. longitude) offshore of Cape Blanc. In comparison with surface chlorophyll seatruth, the DR method was not effective in the determination of chlorophyll off Africa. Interferences caused by suspended particulates of eolian origin in the surface waters plus presumed concentrations of Gelbstoff, resulted in an "enhanced" apparent chlorophyll signal. These interferences can be explained by the following: 1) Increased backscattered radiance was caused by the high concentration of high refractive index (highly reflective) eolian and wave eroded particulates; 2) Inherent optical properties including absorption by dissolved Gelbstoff, attenuation of radiance by sea water and particulate scattering (including multiple scattering) produced a spectral signal that the ratio method could not differentiate from that of chlorophyll; 3) Selective scattering by phytoplankton and high non-selective scattering by the additional particulates in multiple events produced an increased backscattered signal to the DR which was as "enhanced" chlorophyll signature. These apparent chlorophyll signals were investigated in laboratory studies and were found to be principally attributed to the scattering properties of both inorganic particles and algae in suspension.

Although this color ratio did not effectively determine chlorophyll levels, there was a strong correlation between sea surface temperature (SST) gradients and the observed ocean color ratio gradients. Higher ratios were coincident with low temperature, with only a few nearshore exceptions. A significant correlation of this color ratio and total particulates from sea-truth measurements does exist and, in addition, increased fishing was observed to be closely associated with the SST-DR ratio gradients (Tabor 1975). Therefore ocean color changes associated with sea-surface temperature gradients are indicative of productive water masses off the NW coast of Africa. 


\section{CAPE BLANC}

The hydrography between Cape Blanc and Cape Timiris can be described by the T-S diagram based on 16 stations (Allain [1970]) where data were collected between 0 and $800 \mathrm{~m}$. Two main formations of water masses can be recognized. The first is within the upper $300 \mathrm{~m}$ and can be considered a mixture of surface water and Central South Atlantic water with values of $12^{\circ} \mathrm{C}$ and $35.35^{\circ} \%$ at $300 \mathrm{~m}$. The layer between 400 and $800 \mathrm{~m}$ consists mainly of Central North Atlantic water with temperatures between 12 and $8^{\circ} \mathrm{C}$. The influence of Antarctic Intermediate Water is shown by water with a salinity of $35.05^{\circ} \%$ and a temperature of $7^{\circ} \mathrm{C}$. Upwelling in this area is limited for water types with temperatures between $18.5^{\circ} \mathrm{C}$ and $20.5^{\circ} \mathrm{C}$ and salinities between 35.8 and $35.95^{\circ} \%$, which show that the upwelling has its origin in the upper $100 \mathrm{~m}$.

The upwelling in the vicinity of Cape Blanc is persistent throughout most of the year and is evident by the high concentrations of chlorophyll noted in Figures 3 and 4 . A survey of fish tonnages between Cape Blanc and Cape Timiris was made by Boley (1974) in July of 1973. High concentrations of fish were observed west of Cape Blanc while very high tonnages were noted near Cape Timiris. The tonnages of fish therefore, show some correlation with surface chlorophyll concentrations in this area.

During the 4 September 1973 overpass, Skylab collected radiometric data with the S190A Multispectral Camera, the S190B Earth Terrain Camera and the S192 Multispectral Scanner. The ground coverage provided by these sensors is shown in Figure 5. During the subsequent Skylab 4 mission, photographs were also taken of the study area with hand-held cameras.

Figure 6 is a high resolution color photograph of the Banc d'Arguin taken with S190B Earth Terrain Camera. The scale of the photograph is approximately $1: 900,00$ in covering an area of $110 \times 110 \mathrm{Km}$. There is an obvious color gradient of blue to green from offshore to nearshore waters indicative of the presence of suspended material and Gelbstoff. Figure 7 is the green band S190A multispectral camera image having a response region between 0.5 and $0.6 \mu \mathrm{m}$. The scale of this photograph is roughly $1: 2.7$ million covering an area of $157 \times 157 \mathrm{Km}$. The patterns and patchiness of offshore suspended material are evident from this photograph.

The nearshore patterns of suspended material indicate a northerly flow of waters toward Cape Blanc. The "U-shaped" plankton patch southwest of the Cape, indicates a southerly drift of waters from north of the Cape. Using dynamic topography, Fedoseev (1970) discussed the geostrophic circulation of surface waters in the shelf region and concluded that quasi-stationary gyres are formed in the eastern boundary of the Canary Current. The most stationary gyre south of Cape Blanc was observed throughout the year and the offshore patterns noted in the Skylab images are influenced by the flow of the gyre.

Szekielda (1974) reports that plankton patchiness varies especially with the change of seasons. A strong gradient of chlorophyll and/or plankton offshore of Cape Timiris is connected with the converging water masses from the Banc d'Arguin and has been detected in all four seasons. Figure 8 shows the location of offshore ocean color boundaries as derived from LANDSAT-1 and Skylab. The southern gradients show seasonal positions between 1972 and 1974. Besides small-scale fluctuations, the gradient shifts over a maximum distance of only about $16 \mathrm{Km}$. This is an indication that the offshore gradient is a fairly permanent feature.

The enclosed lines south of Cape Blanc, are the relative positions of the "U-shaped" suspended material patch observed from Skylab 3 and 4. Between September 1973 and January 1974, the patch experienced a broadening and shoreward movement. This may be a result of a seasonal change in the circulation. 
Channel 13, of the multiscanner scanner of Skylab, recorded emitted thermal radiation from the surface of the earth. For the Cape Blanc overpass, the radiation data were converted to blackbody temperatures and a histogram was generated by the Johnson Space Center as shown in Figure 9. Classifications were chosen and a color-coded image was produced corresponding to different temperature intervals. Figure 10 is a color-coded temperature map of the waters offshore of Cape Blanc. The temperatures have not been corrected for atmospheric effects, however, the relative temperature gradients can be used to locate the origin of upwelled waters. The cold patch of water in Figure 10 is shown to be roughly between 7 and $11^{\circ} \mathrm{C}$. Coldest known upwelling water off the African coast has only been reported to be as low as $14^{\circ} \mathrm{C}$. Therefore it is estimated that the calculated blackbody temperatures are at least 4 to $6^{\circ} \mathrm{C}$ colder than actually present. Since the cold patch directly corresponds to the "U-shaped" suspended material pattern observed in the imagery, this is undoubtedly a source of upwelled water. In September of 1972, Dr. Ballester (Szekielda, 1974) observed a strong gradient of temperatures and fluorescence to the southwest of Cape Blanc. The temperature distribution is shown in Figure 11. The temperature gradient offshore of Cape Blanc is located in the same area as the cold patch we observed from Skylab.

As described previously, ocean color changes associated with sea surface temperature gradients indicate productive water masses in this region. The Skylab spacecraft was effective in recording these gradients and it can therefore be determined that an intensive area of upwelling was present in September of 1973. By correlating the observed ocean color changes with the low temperature readings, an obvious area of productive waters was apparent offshore of Cape Blanc.

\section{CONCLUSIONS}

The spectral properties of the upwelled waters off the NW coast of Africa have been studied with observations derived from aircraft and Skylab. Results of the aircraft study indicate that the two-channel, ratio approach is ineffective in determining surface chlorophyll concentrations and should not be used in future studies. Ocean color boundaries and temperature gradients were found to be directly correlated with each other and also with fishing effort in the upwelling region. Photographic and scanner data derived from Skylab has been effective in locating ocean color boundaries and mapping temperature distributions. Both can be utilized in this region to qualitatively determine areas of biological productivity. This simple correlation may be applicable in future efforts toward fishery resource management in upwelling areas.

\section{ACKNOWLEDGMENTS}

Portions of this research were sponsored by NASA under Contract No. NAS9-13344. We would like to acknowledge the assistance provided by the University of Washington during the JOINT-I project from February through March 1974. 


\section{REFERENCES}

Allain, C. (1970). Les conditions hydrologiques sur la bordure Atlantique de l'Afrique du nord-ouest. Rapp. P. v. Cons. Explor. Mer. 159, 25.

Arvesen, J. C., Millard, J. P. and Weaver, E. C. (1973). Remote Sensing of Chlorophyll and Temperature in Marine and Fresh Waters. Astronautica Acta. Vol. 18, 229-239.

Boley, M.T. (1974). Compte-Rendu De La Mission Tassergal, Cap 73-11, 9 au 23 Juillet 1973. CINECA Newsletter, Int. Council for the Expl. of the Sea, Charlottenlund Castle, Denmark. 62-67.

Clarke, G. L. and Ewing, G. C. (1974). Remote Spectroscopy of the Sea for Biological Production Studies. In Optical Aspects of Oceanography, Julva, N. G. and E. Steeman Nielsen, eds. Academic Press, New York, N. Y. 389-412.

Duntley, S. Q. (1972). Detection of Ocean Chlorophyll from Earth Orbit. 4th Annual Earth Res. Program Review, Vol. IV, NOAA and NRL Programs, January 17-21, 1972. NASA, Manned Spacecraft Center, Houston, Texas, 1-25.

Fedoseev, A. (1970). Geostrophic Circulation of Surface Waters on the Shelf of North-West Africa. Rapp. P.-v. Cons. Explor. Mer. 159, 32-37.

Lorenzen, C. J. (1970). Surface chlorophyll as an index of the depth, chlorophyll content, and primary productivity of the euphotic layer. Limnol. \& Oceanogr. 15, 479-480.

Ryther, J. H. (1969). Photosynthesis and Fish Production in the Sea. Science, Vol. 166, No. 3901, 72-76.

Szekielda, K-H. (1973). Distribution Pattern of Temperature and Biomass in the Upwelling Area Along the NW Coast of Africa. ASP Fall Conv., Lake Buena Vista, Fla. 664-716.

Szekielda, K-H. (1974). Observations of Suspended Material from Spacecraft Altitudes. Deutsche Hydrographische Zeitschrift, Jahrgang 27, 1974, Heft 4, 159-170.

Tabor, P. (1975). Evaluation of Chlorophyll Measurements by Differential Radiometry from Aircraft Altitudes. Master's Thesis, College of Marine Studies, University of Delaware, $194 \mathrm{p}$.

Yentsch, C. S. (1960). The Influence of Phytoplankton Pigments on the Color of Seawater. Deep-Sea Res. 7, 1-9. 


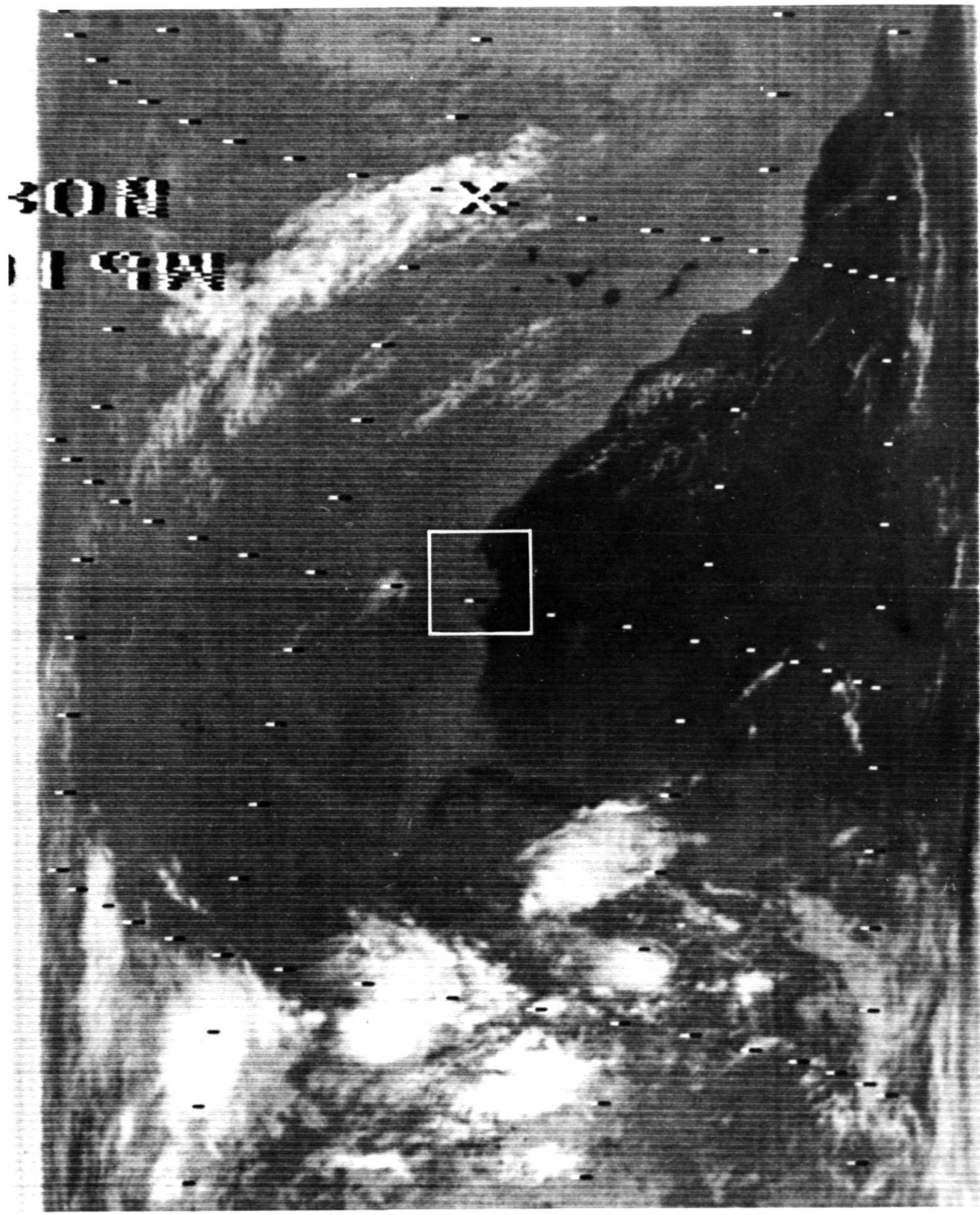

Figure 1. Nimbus 5 thermal image of the NW coast of Africa taken 2 September 1973. Cape Blanc is located within the enclosure. 


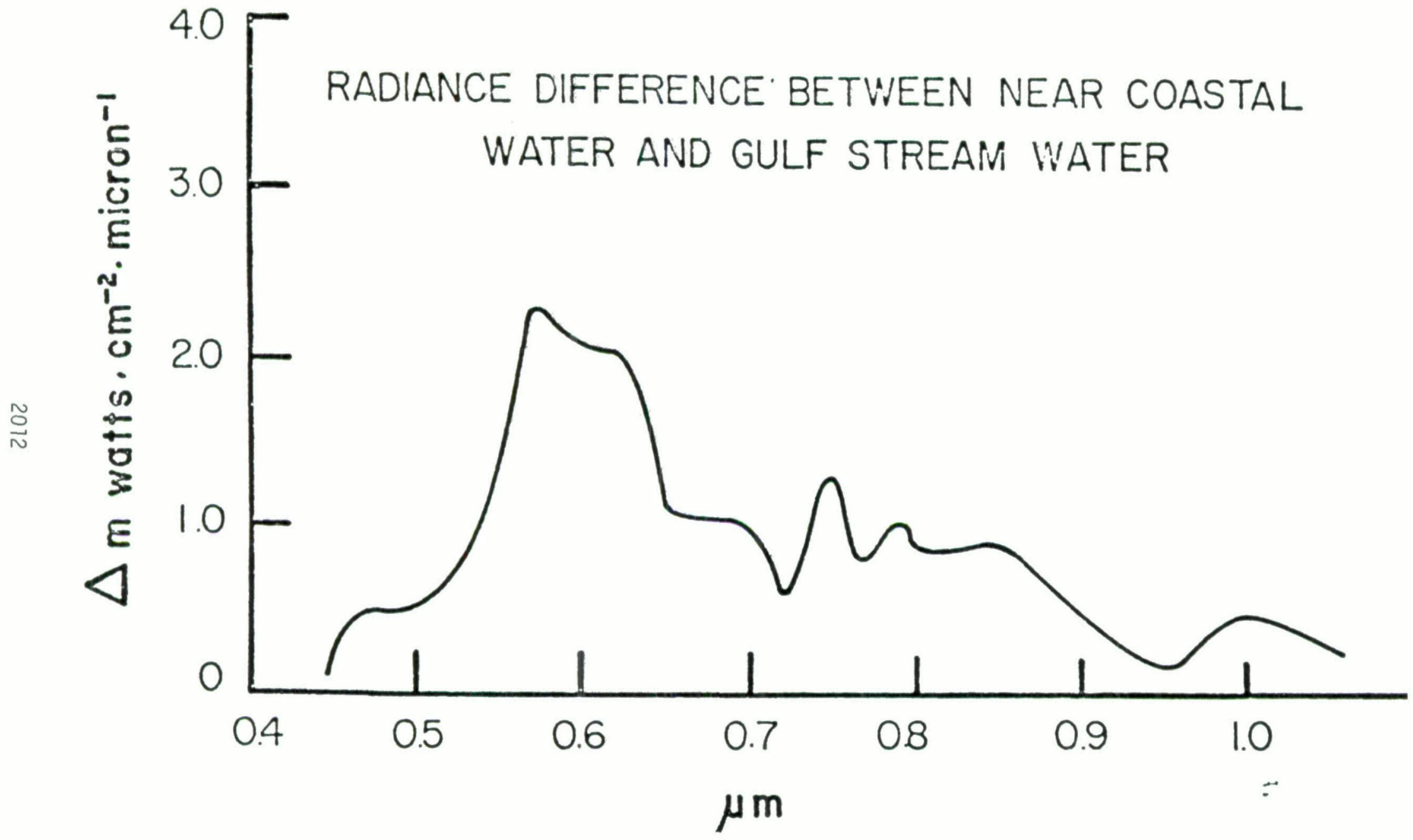

Figure 2. Wavelength dependent radiance caused by particulate and dissolved matter. (from Szekielda (1974)). 


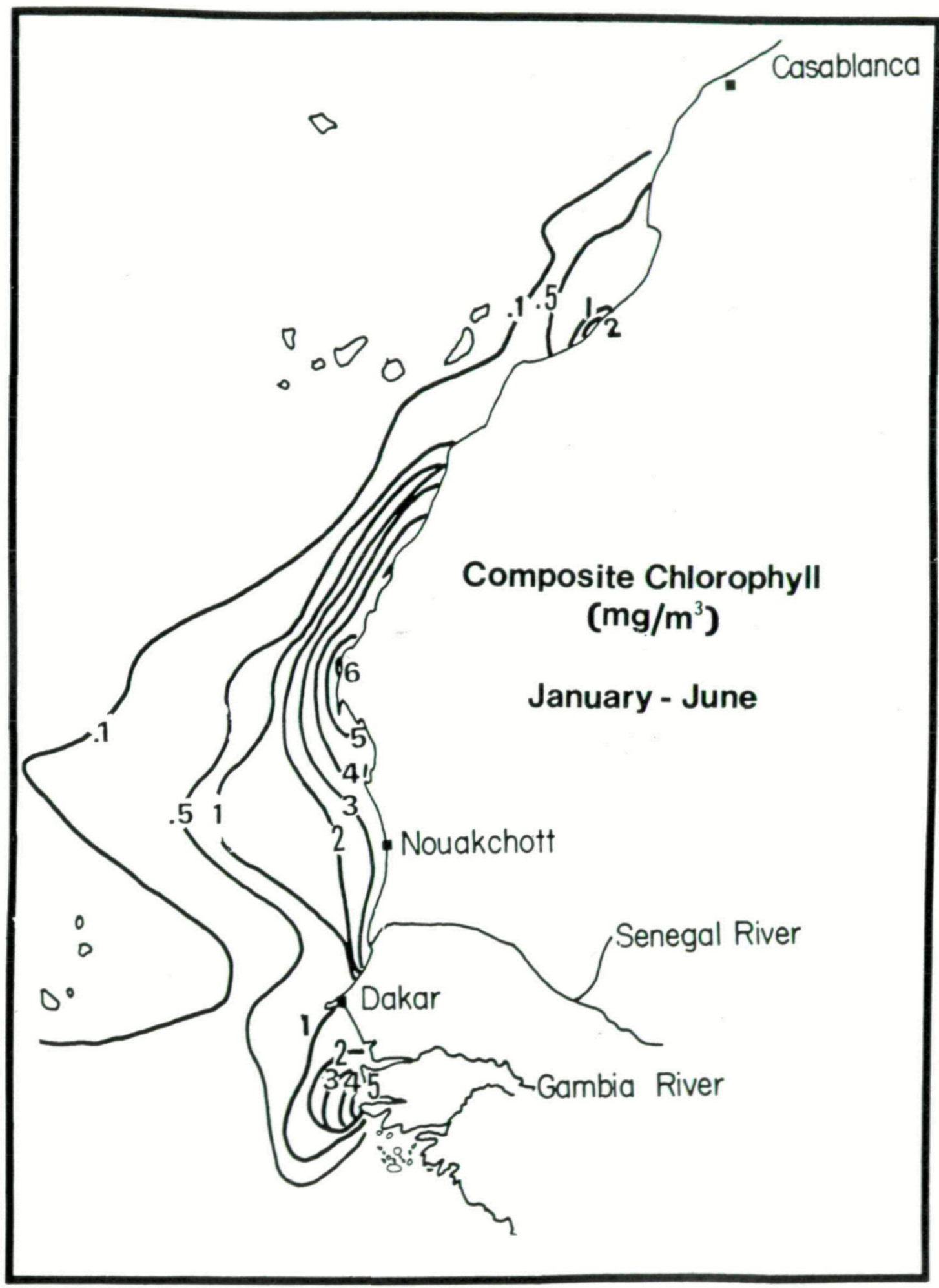

Figure 3. Composite of chlorophyll concentrations for the months January - June. 


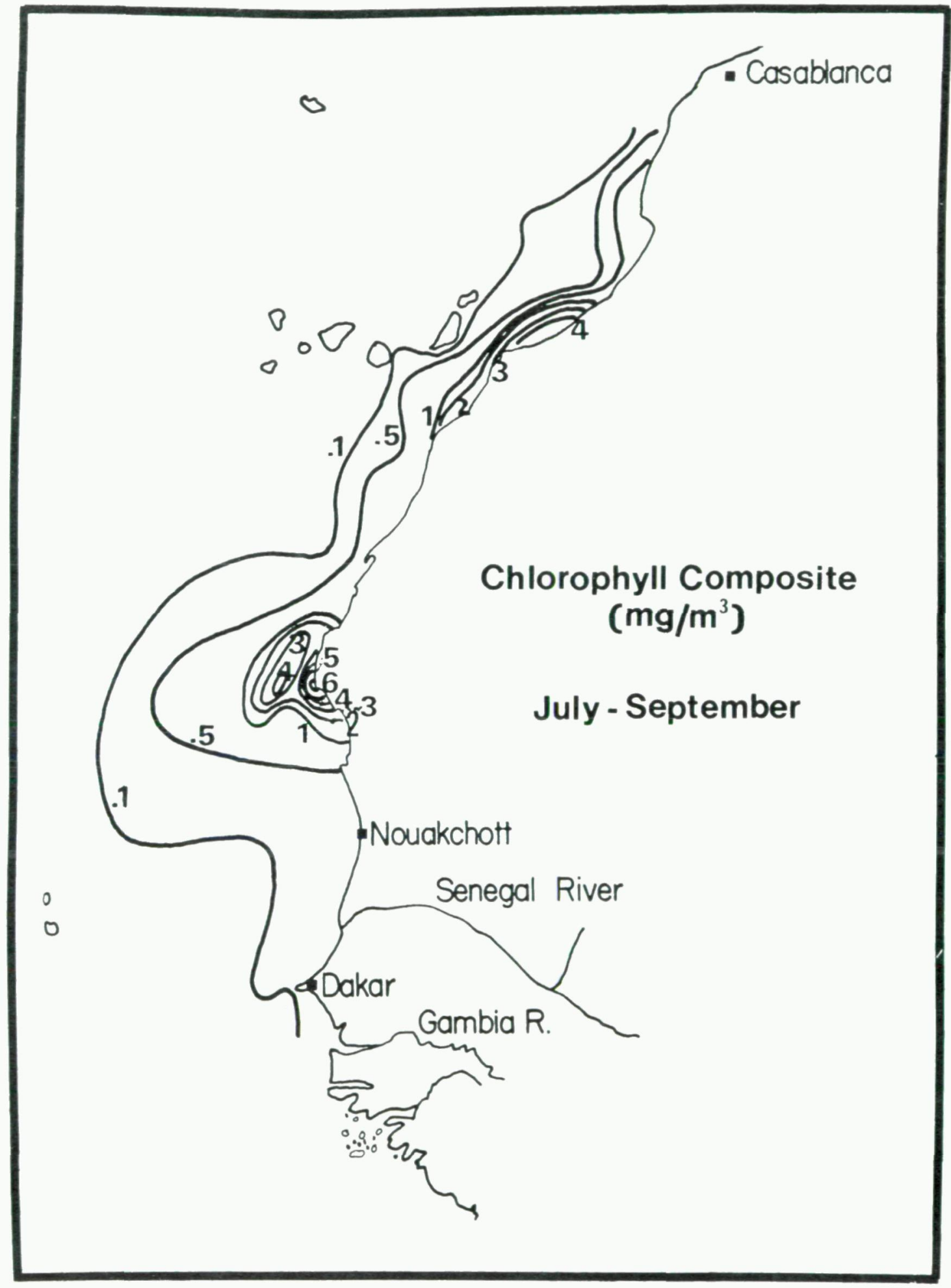

Figure 4. Composite of chlorophyll concentrations for the months July - September. 


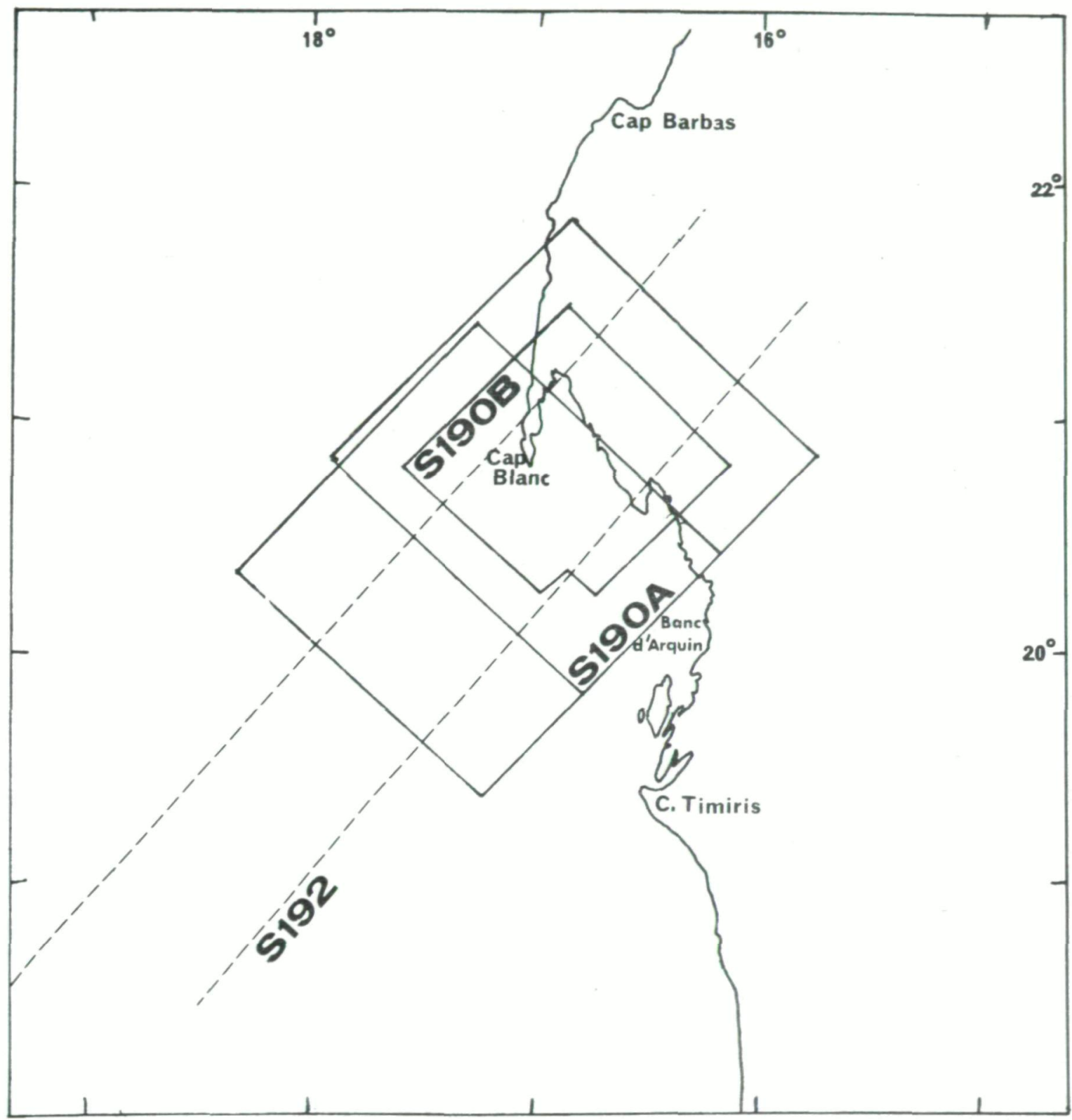

Figure 5. Ground coverage provided by the Skylab sensors during the 4 September 1973 overpass. 


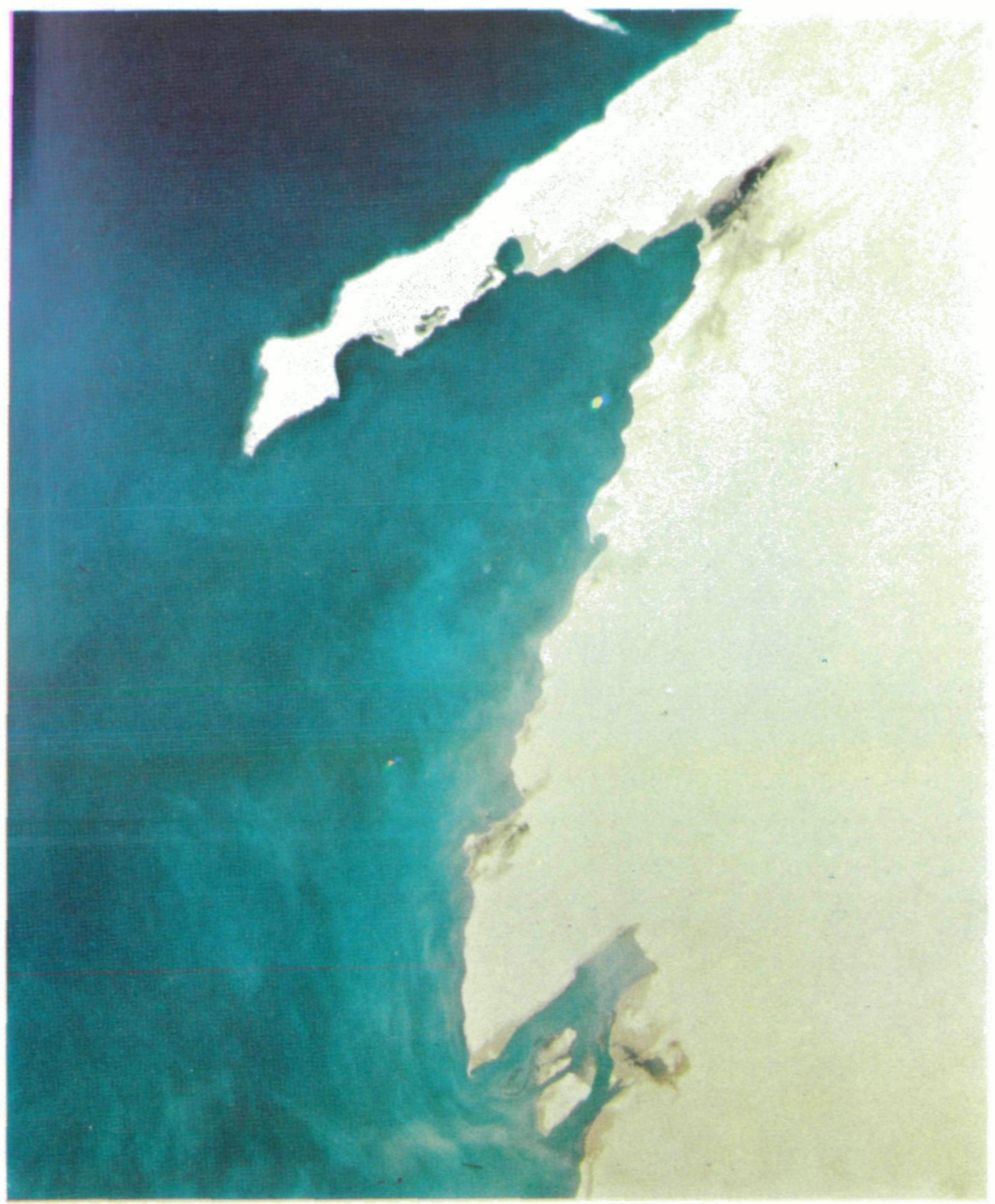

Figure 6. S190B color photograph of Cap: 'anc. 


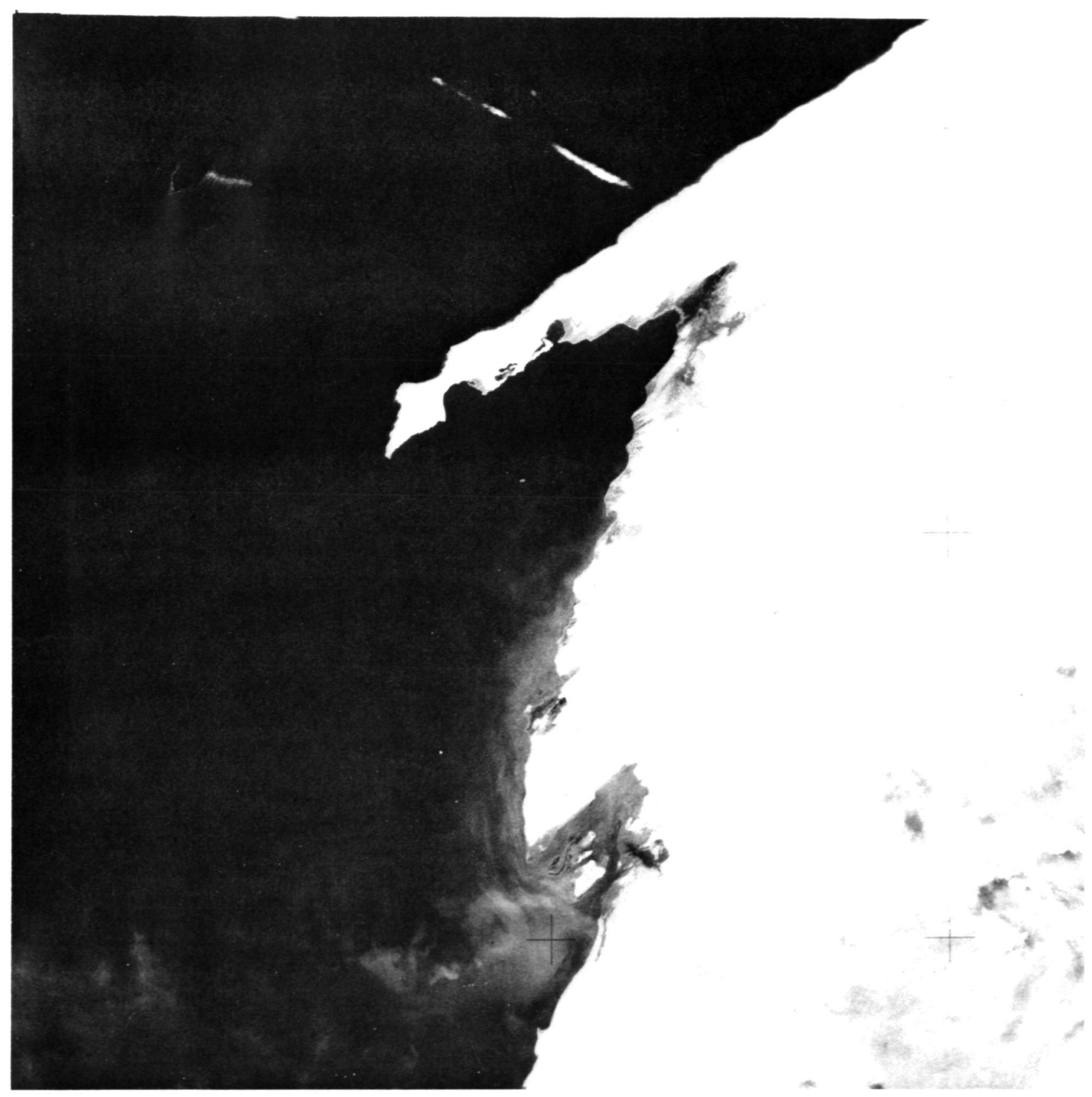

Figure 7. Green band S190A image of Cape Blanc. 


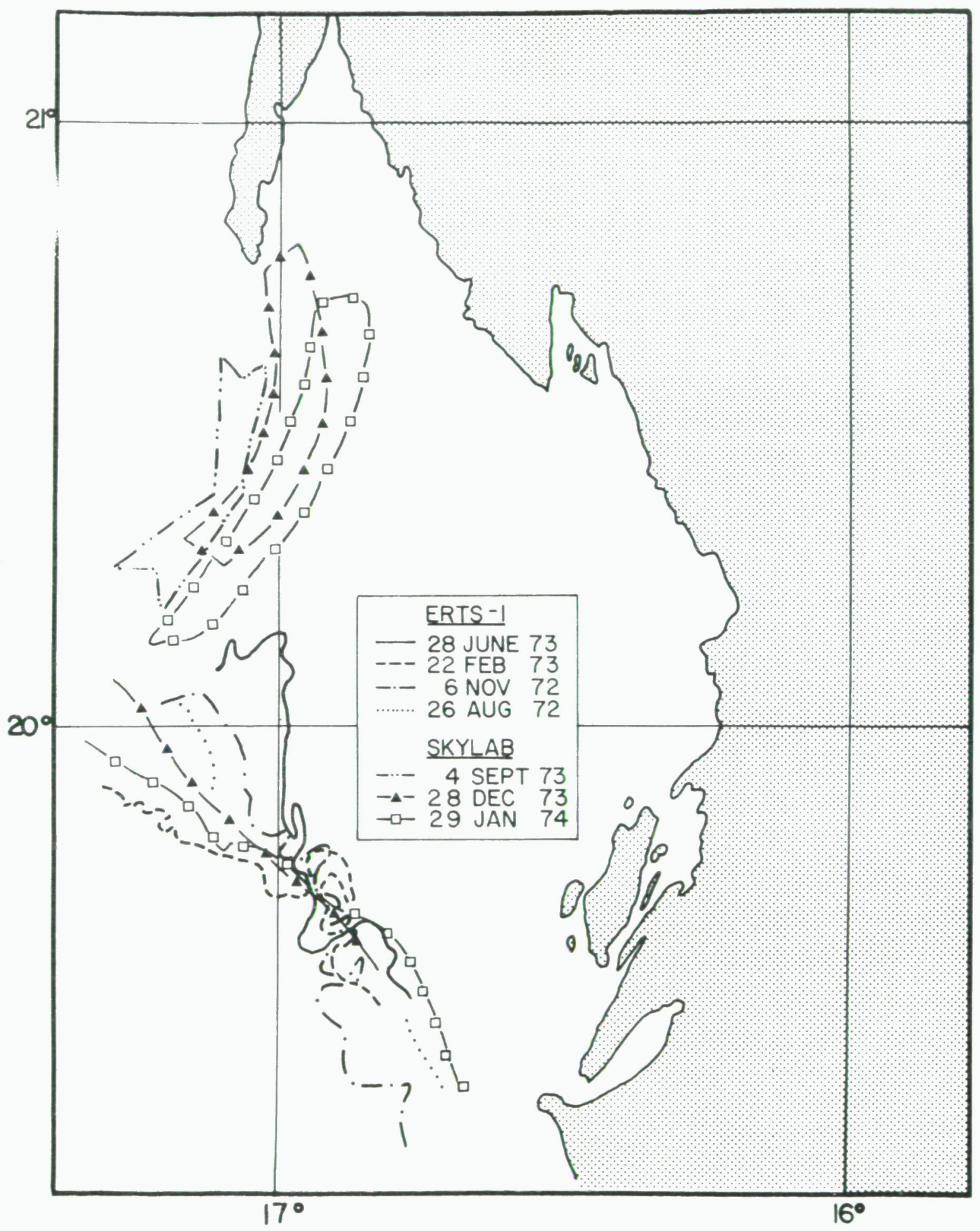

Figure 8. Offshore ocean color boundaries derived from LANDSAT-l and Skylab. 


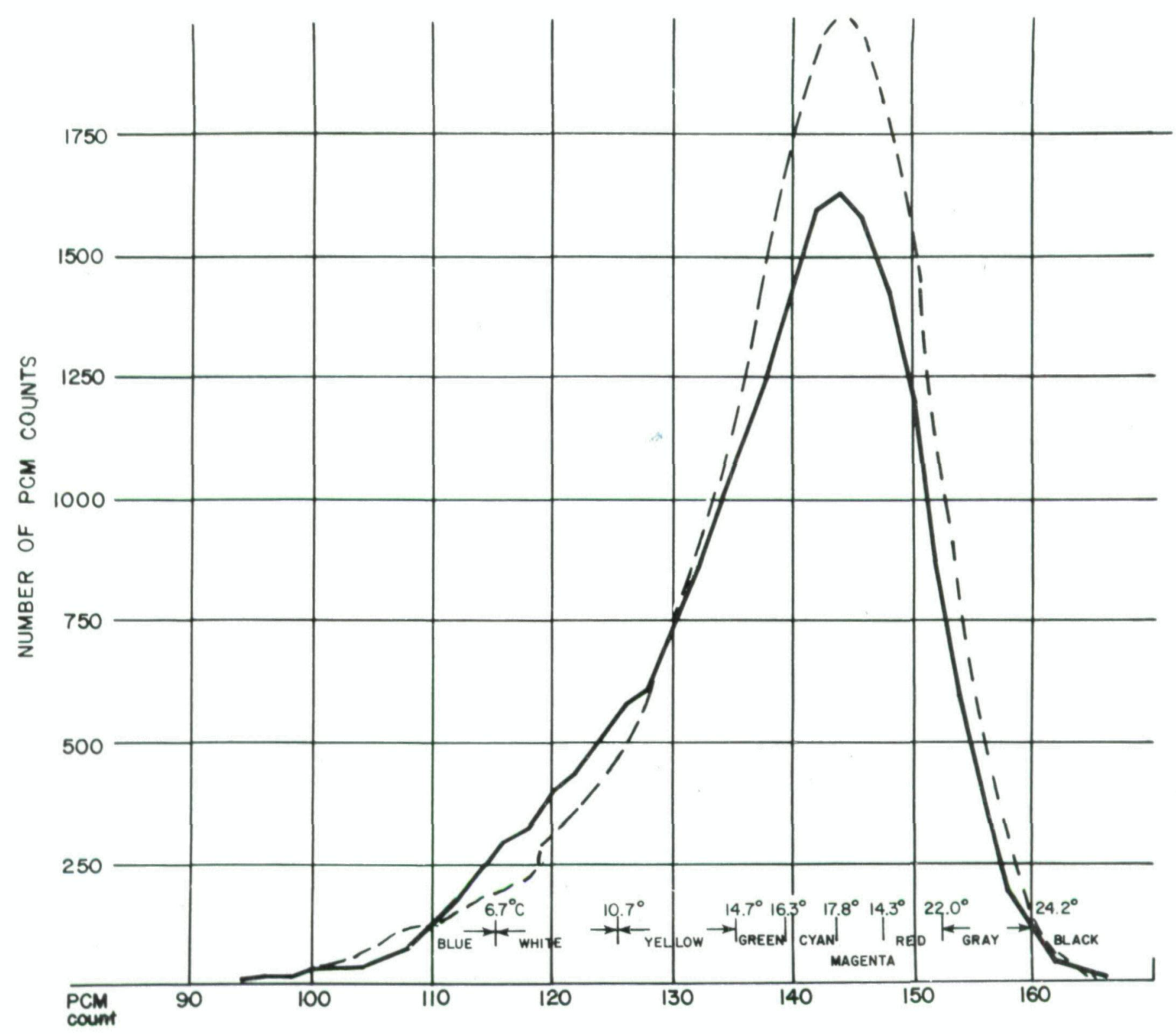

Figure 9. Histogram of thermal data and color coding for S192 imagery. 


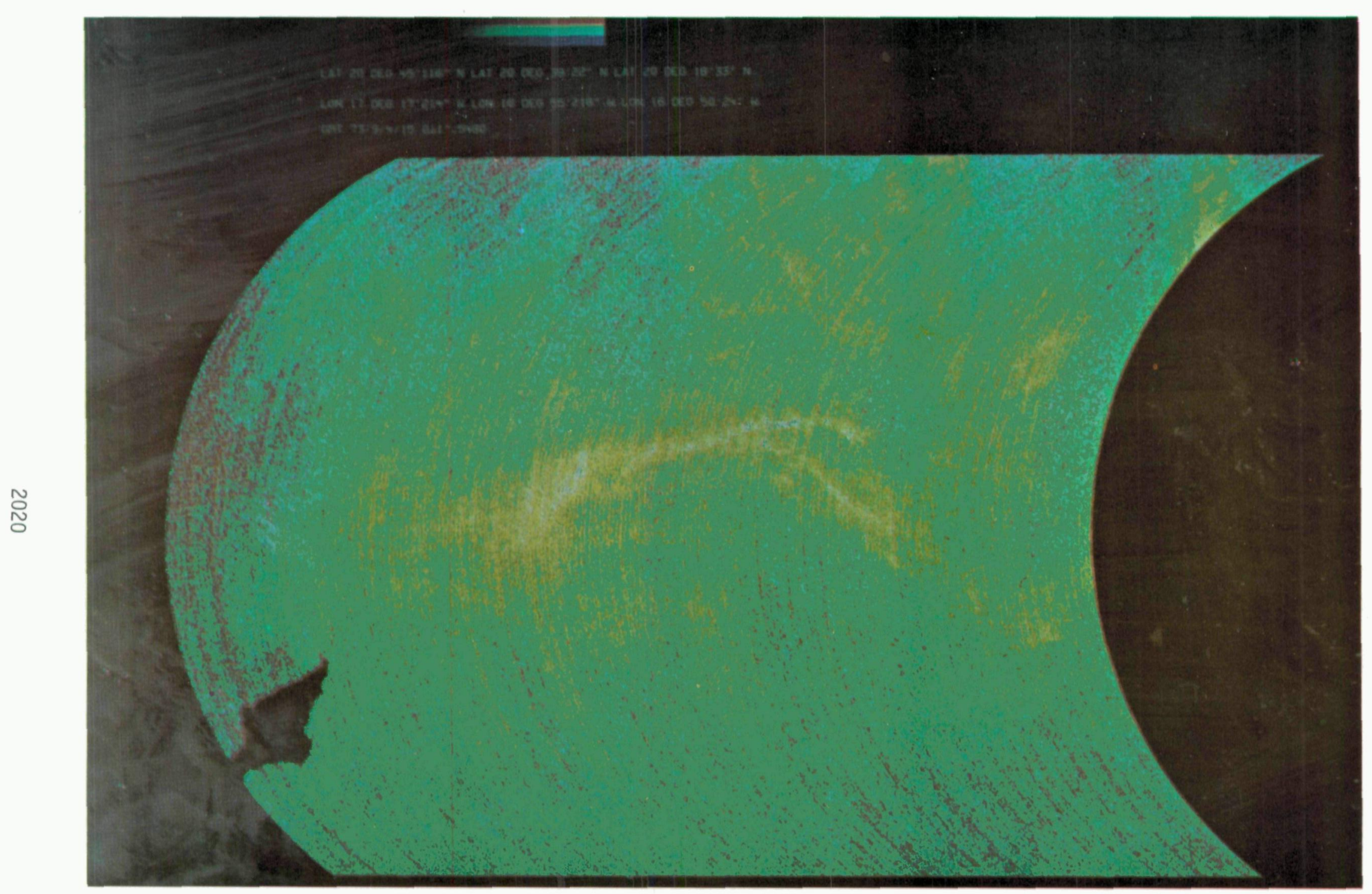

Figure 10. Color-coded temperature distribution derived from channel 13 of the $\$ 192$ multispectral scanner. 


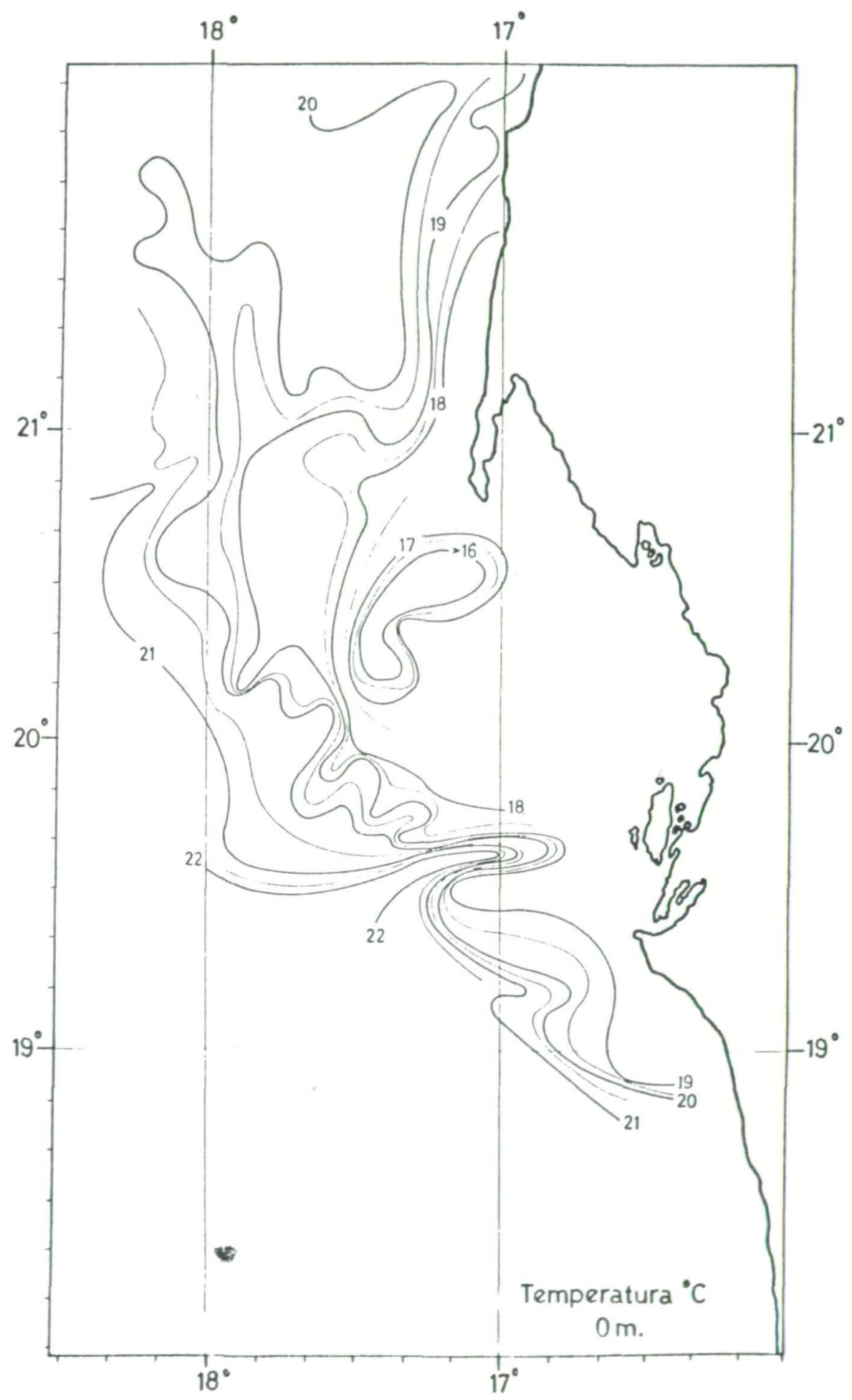

Figure 11. Temperature distribution between Cape Blanc and Cape Timiris observed in September 1972. (from Szekielda (1974)). 